CASE REPORT

\title{
Hookworm in the terminal ileum:a common cause of severe anaemia residing in a rare location
}

\author{
Rup Jyoti Chandak ${ }^{1}$, Archana Thakur ${ }^{1}$, Sukrit Sud ${ }^{1}$, Bibhabhati Mishra ${ }^{1}$, Vinita Dogra ${ }^{1}$
}

\begin{abstract}
Adult Hookworms usually live in the duodenum and jejunum and can be recovered endoscopically for the diagnosis of chronic anaemia. This report describes an interesting case where adult hookworm (Ancylostoma duodenale) was recovered from the terminal ileum by colonoscopy in an old female patient suffering from chronic severe anemia. Her upper gastro intestinal endoscopic findings were normal and fecal occult blood test was positive. The colonoscopic finding was further confirmed by the presence of characteristic eggs of hookworm in stool microscopy and she was treated with anthelminthic along with symptomatic measures. Her clinical condition as well as the blood profile showed much improvement after treatment. Thus, colonoscopy should be considered for the presence of hookworms if the upper endoscopic findings are normal in a clinically suspected patient. J Microbiol Infect Dis 2017; 7(2): 98-100
\end{abstract}

Keywords: Hookworm, colonoscopy, ileum, anemia

\section{INTRODUCTION}

Hookworm is widely distributed in all tropical and sub-tropical countries, affecting more than 576 million people across the globe. When left untreated, hookworms cause internal blood loss leading to anaemia and malnutrition [1]. The adult worm lives in the small intestine of man particularly in the jejunum, sometimes in the duodenum [2] but rarely parasite may be found in other locations of intestine like ileum [3] caecum $[3,4]$ or colon [5] or sometimes outside intestine as high as gastric antrum[6] Here we present an unusual case report of severe anaemia where the hookworm was recovered from terminal ileum through colonoscopy.

\section{CASE REPORT}

A 61-year-old housewife residing in a small village in Faridabad district, sometimes visiting farms, complained of fatigue, generalized weakness, frequent low grade fever and exertional dyspnea for the last 8-9 months. She was diagnosed as a case of iron deficiency anemia (cause under evaluation) in E.S.I hospital and had received 3 units of blood transfusion. Her blood investigations revealed Haemoglobin $(\mathrm{Hb}) 1.6 \mathrm{~g} / \mathrm{dl}$, total leucocyte count
$14,300 / \mu \mathrm{l}$, neutrophils $60 \%$, lymphocytes $37 \%$ monocytes $11 \%$, and eosinophils $15 \%$, Platelet 4.27 lacs/ $\mu \mathrm{l}$, Peripheral smear showed anisocytosis and microcytic hypochromic anemia with no parasites. The total iron was $16.3 \mu \mathrm{g} / \mathrm{dl}$, TIBC (Total Iron Binding capacity) $352 \mu \mathrm{g} / \mathrm{dl}$, Transferrin $335.7 \mu \mathrm{g} / \mathrm{dl}$, \% saturation was 4.6 , vitamin B12 level was $525 \mathrm{pg} / \mathrm{ml}$ and Ferritin level was $6.1 \mathrm{ng} / \mathrm{ml}$. Stool microscopy for presence of parasite was not done however Fecal occult blood test (FOBT) was positive. Upper gastrointestinal endoscopic study was normal. Other investigations including Chest Xray, ultrasonography, kidney function test, liver function test were also normal. However, no definitive diagnosis could be made. She was referred to Gobind Ballabh Pant institute of Medical Education and Research (G.I.P.M.E.R) for colonoscopy.

On colonoscopy the mucosa and vascular pattern of ileum was normal with no ulcer/polyp/growth but few tiny S-shaped white worms were seen invading the mucosa of the terminal ileum with blood oozing points (Figure1) The worms were retrieved from the bowel and sent to the Microbiology laboratory for identification and the ileal tissue was sent for

\footnotetext{
${ }^{1}$ Department of Microbiology, Gobind Ballabh Pant Institute of Post Graduate Medical Education and Research, New Delhi, India

Correspondence: Dr. Rup Jyoti Chandak, Department of Microbiology, Gobind Ballabh Pant Institute of Post Graduate Medical Education and Research, New Delhi, India, Email: rupjyotichandak@yahoo.com Received: 14 October 2016, Accepted: 07 February 2017

Copyright (C JMID / Journal of Microbiology and Infectious Diseases 2017, All rights reserved
} 
histopathology. On naked eye examination, the worm was greyish white around $8-10 \mathrm{~mm}$ in size .Under microscope the worm was unsegmented, cylindrical with both ends pointed and anterior end bending in the same direction as the body curvature suggestive of Ancylostoma duodenale in morphology. Histopathology report showed mild ileitis.

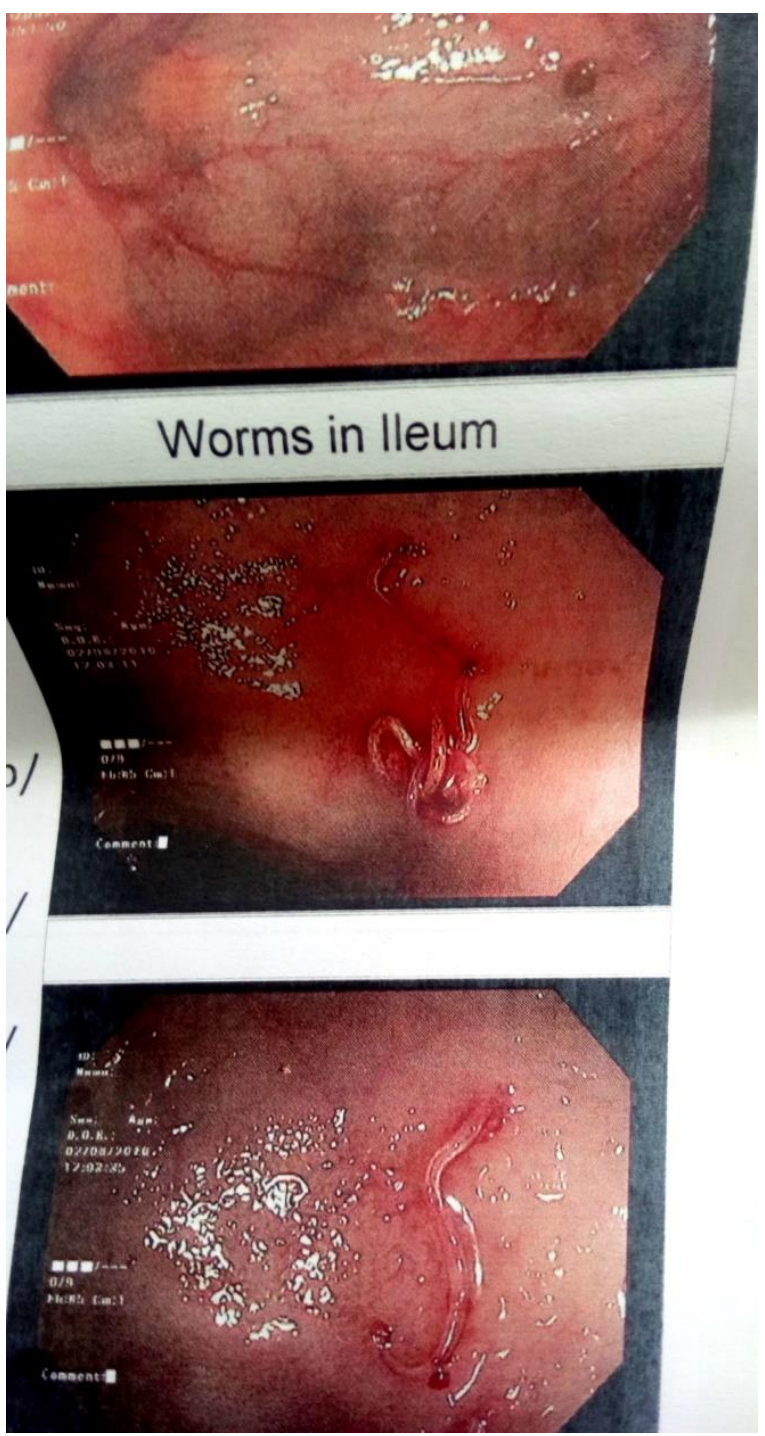

Figure1. Colonoscopic image showing worms in the ileum.

To confirm the diagnosis of hookworm infestation, the patient was asked to submit stool samples on three consecutive days. Grossly, the stool was dark in color, normal in consistency with no fresh blood and no helminthic appendages were visible with naked eyes. On microscopic examination, numerous oval, colorless (non-bile stained) eggs containing segmented ovum with 4 blastomeres and a thin shell membrane were seen, thus confirming the diagnosis of hookworm infestation (Figure 2).
Patient was treated with Albendazole $400 \mathrm{mg}$ for three days supported with iron supplement and multivitamins for 3 months. On follow-up of the patient after one month, she showed good recovery from her symptoms and her physical condition improved.

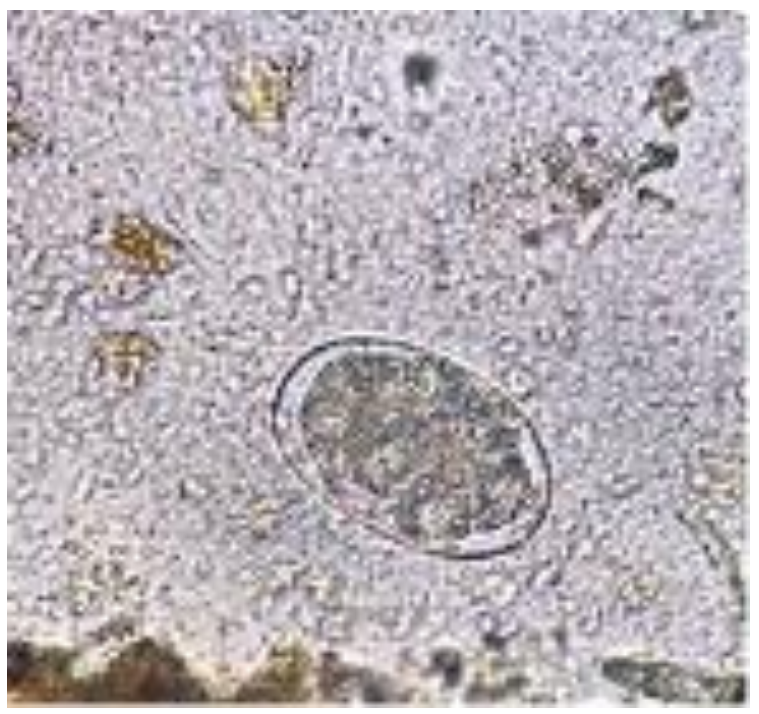

Figure2: Wet mount of stool (40X) showing egg with segmented ovum.

\section{DISCUSSION}

The adult hookworm resides in the small intestine sucking $0.01-0.03 \mathrm{ml}$ blood/day, depending upon the species infecting [7]. Manifestation may range from clinically asymptomatic to chronic blood loss and chronic iron deficiency anaemia, depending upon the body iron store, worm burden and duration of infection [8]. Acute heavy hookworm infection usually presents with bloody or tarry stool whereas occult blood in stool is associated with chronic infection [9].

The diagnosis is usually made by the characteristic clinical history, blood investigations such as microcytic hypochromic anemia along with eosinophilia and presence of characteristic egg on fecal examination, but sometimes there can be absence of eosinophilia and absence of eggs on stool microscopy, especially in early stages of infection [9]. Other modality helpful in a clinically suspected case is upper gastro intestinal endoscopy, which detects parasites in their habitat. Apart from cases where hookworms have been recovered from duodenum and jejunum through upper gastro intestinal endoscopy [9-15], retrieval of hookworms from rare sites of intestine like ileum [3] caecum [3-4],colon [5] or even outside 
intestine(gastric antrum) [6] has also been reported by some workers. The ectopic localization in the antrum has been attributed to jejuno-duodeno-gastric reflux [5] while the recovery of hookworms from the cecum in one report [4] has been attributed to bowel preparation leading to washing the worms downstream. However, in our case the duodenum and jejunum caecum were normal in upper gastro-intestinal study and parasites were viewed on colonoscopy directly attached to the ileal mucosa itself.

In our case, the patient presented with classical picture of chronic severe anemia with eosinophilia (15\%) and positive FOBT and a normal upper gastro intestinal endoscopy findings. On clinical suspicion when colonoscopy was done, adult hookworms were recovered from the terminal ileum, suggesting the underlying cause of chronic severe anemia. This finding was further supported by presence of characteristic hookworm eggs on stool microscopy. Our case suggests that in such cases of severe anaemia, eosinophilia and positive FOBT, when upper gastrointestinal endoscopic findings are normal, presence of hookworm in ileum should be suspected although it is not a common habitat for the parasite and simple non-invasive tests like stool microscopy should be always be done.

\section{Conclusion}

Thus in a tropical country like India, soil transmitted helminthic infection should always be considered as a differential diagnosis in patients with non-responding iron-deficiency anemia, especially in patients coming from rural areas. Presence of parasite in rare location of intestine such as terminal ileum should be suspected in such patients and colonoscopy should be considered.

\section{ACKNOWLEDGEMENTS}

Declaration of conflicting interests: No competing interests to declare.

Funding: The authors received no financial support for the research and/or authorship of this article.

\section{REFERENCES}

1. https://www.cdc.gov/parasites/hookworm/
2. Chatterjee KD. Class Nematodes Parasitology. In Protozoology and Helminthology in relation to Clinical Medicine, $12^{\text {th }}$ Eds, Calcutta Chatterjee Medical Publications, 1980: 158-207.

3. Deesomsak M, Sawanyawisuth K, Prachayakul V. An unusual cause of chronic diarrhea. Tropical Biomedicine 2014; 31(1): 187-189.

4. Dunzendorfer T, Nunes DP, Kasznica J. More intestinal worms on colonoscopy. Am J Gastroenterol 1996; 91:1677-1678.

5. Thomas V, Harish K, Tony J, Sunilkumar R, Ramachandran TM, Anitha PM. Colitis due to Ancyclostoma duodenale. India J Gastroenterol 2006; 25: 210-211.

6. Dumont A, Seferian V, Barbier P. Endoscopic discovery and capture of Necator americanus in the stomach. Endoscopy 1983; 15:65-66.

7. Feldman M, Friedman LS, Brandt J. Sleisenger and Fordtan's Gastrointestinal and Liver Disease: Pathophysiology, diagnosis, management. Philadelphia: Saunder's Elsevier Publications 2010.

8. Knopp S, Mgeni AF, Khamis IS, et al. Diagnosis of soil transmitted helminthes in the era of preventive chemotherapy: Effect of multiple use of stool sampling and use of different diagnostic technique. Plos Negl Trop Dis 2008; 2:e331.

9. Wu KL, Chuah SK, Hsu CC, Chiu KW, Chiu YC, Changchien CS. Endoscopic diagnosis of hookworm disease of the duodenum: A case report. J Intern Med Taiwan 2002; 13:27-30.

10. Rao C, Sharma A, Rana S et al. Massive obscure overt gastrointestinal: an unusual case by capsule endoscopy. J postgraduate Med Edu Res 2012; 46 (1) $37-39$.

11. Barakat M, Ibrahim N, Ahmed N. In Vivo Endoscopic Imaging of Ancylostomiasis-Induced Gastrointestinal Bleeding Clinical and Biological Profiles. Am J Trop Med Hyg 2012; 87 (4):701705.

12. Hyun HJ, Kim EM, Park SP, Jung J, Chain J, Hong S. A Case of Severe Anemia by Necator americanus Infection in Korea. Korean Med Sci 2010; 25:1802-1804.

13. Bhatia V, Das MK, Kumar P, Arora NK. Infantile hookworm disease. Indian Pediatr 2010; 47 (2):190-192.

14. Zhao Y, Wang L, Si J. Hook worm caused chronic anemia found during the procedure of acute gastrointestinal bleeding: a case report. Cases Journal 2009; 2:105.

15. Cedrón-Cheng H, Ortiz C. Hookworm Infestation Diagnosed by Capsule Endoscopy. J Gastroint Dig Syst 2011; S1 003. 